\title{
ANÁLISE SEMIÓTICA DA MARCA MÃE TERRA: O POTENCIAL COMUNICATIVO DE SUAS EMBALAGENS
}

\section{Semiotic analysis of the brand mãe terra: communication potential of its packaging}

\section{Análisis de semiótica marca la madre tierra: el potencial de su embalaje comunicativa}

\author{
Francine Cruz de Cerqueira Lima ${ }^{1}$ \\ Bárbara Miklasevicius ${ }^{2}$
}

\section{Resumo}

O objetivo desse trabalho é avaliar o potencial de significado das embalagens da marca Mãe Terra. A embalagem de um produto tem função dupla: é uma forma de publicidade e fonte de informação. No caso de alimentos com apelo saudável, como é o caso dos comercializados pela marca analisada, essas duas funções muitas vezes se misturam. Pelo método semiótico, apresenta-se o potencial de significado comunicado pela Mãe Terra aos consumidores em busca de alimentos mais saudáveis.

Palavras-chave: semiótica, embalagem, rótulo, Mãe Terra, alimentos saudáveis.

\begin{abstract}
The objective of this paper is to analyze the potential of meanings in the packaging of the brand Mãe Terra. The packaging of a product has a double function: it is both a type of advertising and a source of information. Considering food products with health and nutrition claims, like the ones produced by the brand studied, these two functions are often mixed. Using the semiotics method, this article presents the potential meaning communicated by Mãe Terra to consumers who seek healthier food.
\end{abstract}

Keywords: semiotics, packaging, food label, Mãe Terra, food products health and nutrition claims.

\footnotetext{
${ }^{1}$ Jornalista pela ECA-USP e mestranda em Nutrição em Saúde Pública na FSP-USP, com 15 anos de atuação profissional na imprensa escrita, principalmente na área de comportamento e saúde. Endereço: Rua Joaquim Antunes, 797/ 63; CEP 05415-012, SP-SP. Telefone: (11) 99754 8711. E-mail: francine.lima@ gmail.com ${ }^{2}$ Relações Públicas pela ECA-USP, com especialização em marketing pela EAESP-FGV e 15 anos de experiência em marketing de grandes empresas, é atualmente mestranda em Administração (Marketing) da FEA-USP. Endereço: R. Dr. Renato Paes de Barros, 322/171; CEP 04530-000; SP-SP. Telefone: (11) 991468609. Emails: bmikla@usp.br / mikla@uol.com.br.
} 
Análise semiótica da marca mãe terra: o potencial comunicativo de suas embalagens

\section{Resumem}

El objetivo de este estudio es evaluar el potencial de significación de los embalajes de la marca Mãe Terra. El envase de un producto tiene doble función: es una forma de publicidad y fuente de información. En el caso de los alimentos con llamadas saludables, tales como los comercializados por la marca analizada, estos dos a menudo se mezclan. Utiliza-se el método semiótico para estudiar el potencial de la comunicación de los embalajes de Mãe Terra para los consumidores que buscan alimentos más saludables.

Palabras-clave: semiótica, embalaje, rótulo, Mãe Terra, alimentos saludables.

\section{INTRODUÇÃO}

Pode-se dizer que a embalagem dos alimentos tem função dupla. De um lado, é uma forma de publicidade, pois traz mensagens elogiosas ao produto e de incentivo ao consumo, seja por meio de frases, imagens, cores ou design. De outro lado, tem função informativa, pois reúne dados sobre o fabricante, a composição do produto, sua origem, datas de fabricação e validade etc. No caso de alimentos com apelo saudável, ou seja, cuja comunicação é voltada a uma parcela do público consumidor interessada em produtos com determinadas características reconhecidas como próprias de alimentos saudáveis, a publicidade e a informação muitas vezes se misturam, completando ou confundindo uma à outra.

Num contexto em que o ambiente alimentar é considerado um dos fatores de maior influência sobre os hábitos alimentares, os tipos de alimentos e a informação aos quais as pessoas têm acesso devem ser previstos pelas políticas alimentares. Favorecer a capacidade das pessoas de diferenciar publicidade de informação e, mais que isso, saber interpretá-los, é uma preocupação constante nas pesquisas sobre rotulagem de alimentos.

\section{OBJETIVO}

Neste trabalho, procurou-se analisar a marca Mãe Terra por meio de suas embalagens. O objetivo geral foi identificar os signos comuns usados nessa comunicação, classificá-los conforme a proposta teórico-metodológica de Charles Peirce, descrita por Perez (2004) e Santaella (2007), e interpretar sua potência de significado. 


\section{APRESENTAÇÃO DO SIGNO}

\subsection{A marca}

A marca Mãe Terra foi escolhida após pesquisa preliminar em uma loja de nicho focada no comércio de alimentos de apelo natural e saudável. A Mãe Terra se destacou por apresentar em suas embalagens grande quantidade de signos cujo propósito era comunicar que a marca só tinha produtos saudáveis e "verdes".

No site da marca (www.maeterra.com.br) há uma lista com todos os produtos: cereais integrais (arroz, cevada, trigo, quinua, amaranto), grãos (feijão), sementes e castanhas (linhaça, gergelim, castanha-do-Pará), temperos (sal, gersal), açúcar, chás, granolas, massas integrais, cookies, sopas desidratadas, macarrão instantâneo, salgadinhos e complementos alimentares.

Os últimos produtos da lista acima são novidades para a Mãe Terra. A empresa, brasileira, começou como um restaurante e uma loja de produtos naturais em São Paulo em 1979, então um segmento c de nicho bastante restrito. A empresa familiar cresceu e ampliou o portfólio de produtos, com vendas no varejo e no atacado, mas continuou pertencendo ao nicho dos "naturebas", com um público mais interessado em saúde do que em conveniência e sabor. Em 2007, foi comprada por jovens empresários, que alargaram o mix de produtos em direção a alimentos processados semiprontos e prontos para o consumo, reposicionaram a marca e apostaram num público mais amplo e jovem. Segundo o sócio Alexandre Borges, na comparação com 1979, estamos numa época bastante mais favorável a produtos como os da Mãe Terra (BARBOSA, 2011).

\subsection{Produtos}

O mix atual de produtos da Mãe Terra inclui (a) os tradicionais alimentos minimamente processados - como os grãos, chás, sementes e castanhas -, (b) ingredientes, como o sal e o açúcar, e também (c) produtos ultraprocessados, como as sopas e salgadinhos. Minimamente processados são aqueles alimentos que passaram por processos mecânicos simples de limpeza, separação de partes não comestíveis, pasteurização, fermentação e ensacamento. Ingredientes são aqueles que não são consumidos sozinhos, 
Análise semiótica da marca mãe terra: o potencial comunicativo de suas embalagens

mas apenas como parte de uma receita. Ultraprocessados são aqueles que foram transformados por processos industriais, misturados com outros alimentos também transformados, muitas vezes envolvendo ingredientes vindos de diversas partes do mundo, e resultam em produtos elaborados prontos para o consumo.

Essa classificação em três grupos de alimentos foi proposta por Monteiro e col. (Monteiro, Levy, Claro, Castro \& Cannon 2010) como uma alternativa à divisão tradicionalmente usada nas pirâmides alimentares, que separava apenas alimentos in natura em cereais, frutas e hortaliças, carnes e ovos, laticínios, gorduras e açúcares, ignorando as formas processadas desses alimentos, cada vez mais presentes nas dietas ocidentais. Usando a classificação antiga, não é possível posicionar a maior parte dos produtos vendidos hoje em supermercados na pirâmide alimentar.

Segundo Monteiro e col. (2010), as dietas mais saudáveis são aquelas em que a proporção de alimentos ultraprocessados consumidos no dia a dia é pequena e os alimentos integrais têm posição privilegiada. Dietas baseadas em alimentos integrais são consideradas mais saudáveis e mais sustentáveis não apenas devido ao seu perfil nutricional superior, mas também pelo aspecto sociopolítico da produção e distribuição globalizadas de alimentos: as indústrias de ultraprocessados são geralmente empresas transnacionais sem nenhum compromisso com soberanias nacionais. Dito de um modo mais amplo, as dietas sustentáveis são aquelas que preservam os sistemas alimentares tradicionais. Assim, na informação ao consumidor sobre alimentos de apelo saudável, essa diferenciação deveria ser considerada.

\subsection{Alimentação e alimentos saudáveis x rotulagem}

A legislação brasileira obriga as marcas de alimentos a incluir nos rótulos a informação nutricional, que consiste numa tabela ou lista com as quantidades e respectivas proporções de determinados nutrientes numa determinada porção do produto (ANVISA 2003). É permitido incluir também, em caráter opcional, alegações de propriedades nutricionais baseadas na informação nutricional numérica, em formas verbais e não verbais (ANVISA 2012). Assim, o fabricante pode inscrever "alto conteúdo de proteínas" ou "baixo teor de sódio" na embalagem de um produto se a presença de proteínas e sódio em valores respectivamente alto e baixo na porção sugerida for declarada numericamente na mesma embalagem. 
Por enquanto, a tabela nutricional e as alegações controladas são as principais fontes de informação que o consumidor tem a seu dispor no momento da compra para concluir se o produto que deseja comprar é saudável ou não, seja essa informação compreensível ou não. Não é comum que os rótulos informem outros aspectos da alimentação saudável, como a extensão do processamento dos produtos, ou o tipo e a quantidade de agrotóxicos usados na agricultura, ou ainda a quantidade de corantes e conservantes usados. Parte significativa da informação sobre os alimentos processados que poderia ser relevante para a escolha do consumidor é omitida na embalagem, pois a legislação isenta os fabricantes de sua declaração.

A lista de ingredientes, por exemplo, apresenta o nome das substâncias que compõem os produtos, mas não inclui a quantidade (absoluta ou relativa) de cada um deles, deixando para o consumidor a tarefa de adivinhar aproximadamente essas quantidades com base em uma regra simples que a maioria das pessoas nem conhece: os ingredientes são listados sempre e necessariamente em ordem decrescente de proporção, ficando os aditivos por último, independentemente da quantidade usada (ANVISA 2002). Se houver açúcar na lista de ingredientes, nem sempre será possível saber em que quantidade ele está presente. Não é obrigatório declarar no rótulo sua quantidade no produto, a menos que se opte por alegar que o produto tem baixo teor ou não adição de açúcar, conforme as regras da RDC 54 (ANVISA, 2012).

De modo geral, a rotulagem dos alimentos processados com apelo saudável procura ressaltar as características dos produtos que atendem às recomendações da Organização Mundial da Saúde (WHO 2004): limitar a ingesta de gorduras totais e saturadas, sal e açúcar adicionado; eliminar a ingesta de gordura trans; e aumentar a ingesta de frutas, hortaliças, legumes, grãos integrais e castanhas. Mas essas recomendações se restringem ao perfil nutricional dos alimentos. A rotulagem nutricional normalmente não fornece informações adicionais que permitam ao consumidor entender de forma mais completa se tais características são suficientes ou não para considerar esses produtos como saudáveis ou como itens que podem ser consumidos com frequência, sem prejuízo ao equilíbrio da dieta.

Para Lobstein \& Davies (2009), as formas normalmente usadas de apresentar o perfil nutricional dos alimentos servem para atrair o consumidor para versões melhoradas de produtos processados e não ajuda a identificar claramente quais são os menos saudáveis. Os autores defendem que formas mais claras de comunicação sejam adotadas para a 
Análise semiótica da marca mãe terra: o potencial comunicativo de suas embalagens

rotulagem de alimentos, de modo que mesmo o consumidor mais desatento seja capaz de identificar quais são as opções menos e as mais saudáveis no mercado.

À primeira vista, parece que a Mãe Terra procura fazer o que Lobstein \& Davies (2009) propõem: seus rótulos são repletos de sinais de que seus produtos são saudáveis e informações que vão muito além dos nutrientes.

Esses elementos foram estudados neste trabalho com o objetivo de identificar a potência de significado gerada.

\section{ANÁLISE SEMIÓTICA}

\subsection{Ponto de vista qualitativo-icônico}

A marca Mãe Terra está explícita e intensamente associada à natureza e procura ser identificada de todas as formas como sinônimo de natural. Todos os signos da marca comunicam essa ideia, a começar pelo nome. "Mãe Terra" remete à "Mãe Natureza" e à própria terra, da qual nascem os alimentos. A identidade visual da marca, uma árvore, reforça essa associação. De acordo com a classificação proposta por Peirce e relatada por Santaella (2007), os signos fundamentados em qualidades (quali-signos), como cores e formas, são chamados de ícones e relacionam-se com seu objeto por meio da semelhança e das sensações. Os símbolos são fundamentados em convenções (adotadas aleatoriamente). A árvore-símbolo da Mãe Terra é a um só tempo ícone, por sua semelhança com uma árvore real, e símbolo, por sua associação clássica à natureza. Para que não haja escape, essa identificação é reforçada mais uma vez por meio do slogan, logo abaixo da raiz da árvore: "natural de verdade".

As palavras que compõem o nome da marca são ligadas ao arquétipo da figura materna. A mãe é a cuidadora por natureza na estrutura familiar, enquanto Terra é o nome do planeta em que surgimos e nos desenvolvemos. O nome, então, textualmente, remete a carinho, a origem, a algo que "protege e cuida de seus dependentes e daqueles que estão sob seus cuidados" (BATEY, 2010).

Nas embalagens, quase tudo significa "natural". A maioria delas tem fundo branco, ilustração de tema bucólico remetendo ao campo, uso da cor verde e de tons terrosos em vários elementos, tipografia delicada, diversos símbolos associados a informações nutricionais e referências diretas ao que é natural e caseiro. 
Análise semiótica da marca mãe terra: o potencial comunicativo de suas embalagens

A parte da frente da embalagem da Granola Caseira Tradicional em versão sem adição de açúcar da Mãe Terra (Figura 1), tomada aqui como exemplo, está repleta de ícones. As cores mais marcantes da embalagem (branco, verde e marrom) são ícones que, por meio da sensação de leveza (branco) e da semelhança com as cores das plantas (verde e marrom), remetem diretamente à natureza e indiretamente à alimentação natural. Ao pé do pacote, uma ilustração mostra uma casa simples no meio de um vasto campo verde. $\mathrm{O}$ desenho, também ele um ícone, remete a uma zona rural bucólica e mistificada, isolada da modernidade, onde parece não haver máquinas nem processos industriais.

A estampa de toalha de mesa "de avó" contribui para transmitir esse clima tranquilo de casa de campo onde não há pressa, estresse ou medo.

Fig. 1 - Frente da embalagem da Granola Caseira Tradicional Mãe Terra e os signos da marca identificados pelas autoras.

Fonte:http://www.maeterra.com.br/site/index.php?mact=News, cntnt01,detail,0\&cntnt01art $\underline{\text { icleid }=47 \& \text { cntnt } 01 \text { returnid }=68}$

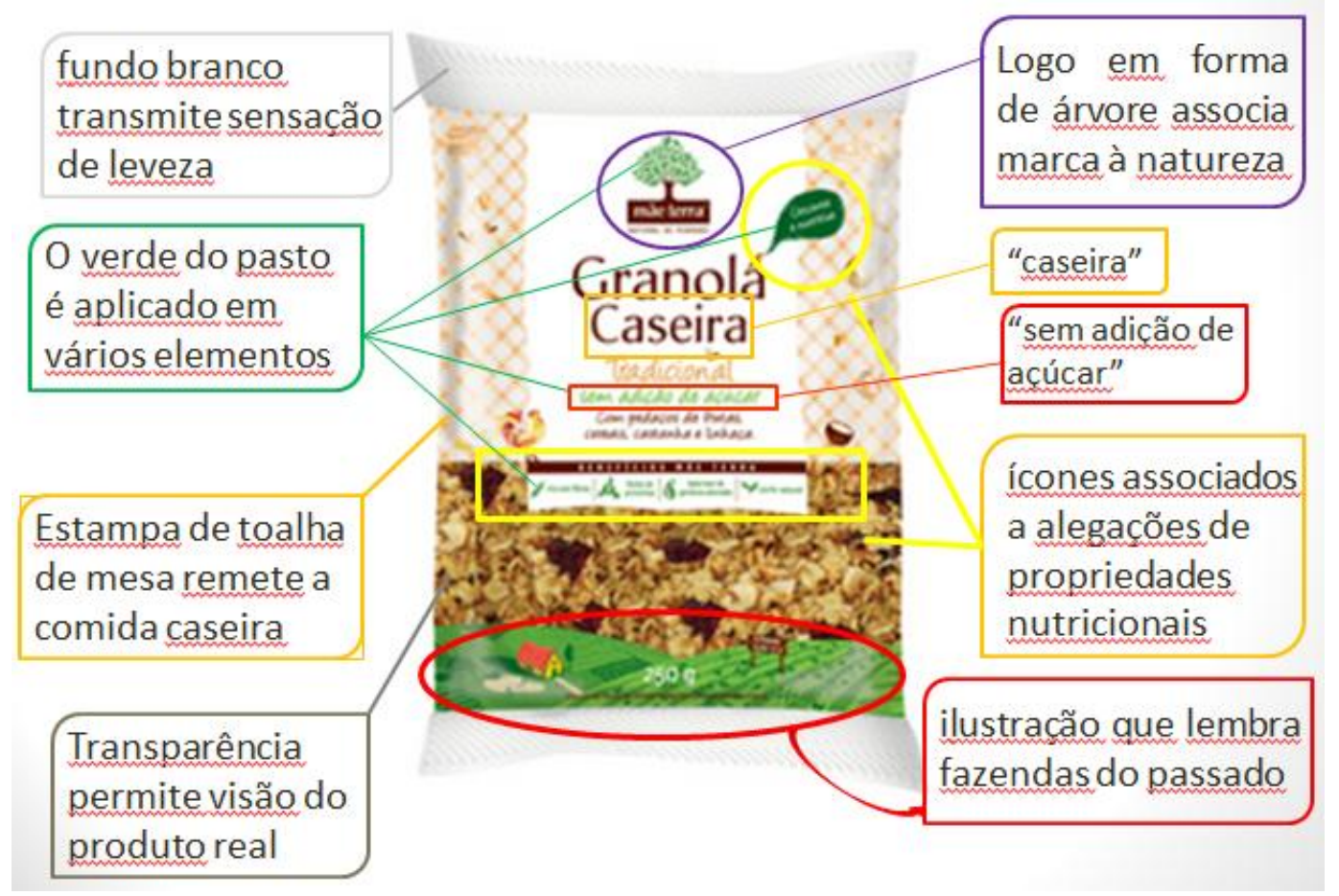

A maior parte dos produtos é acondicionada em sacos similares aos da granola (Figura 1), sem caixa externa, o que também evoca simplicidade. 
Fig. 2 - Verso da embalagem da Barra de Cereais Mãe Terra e os signos.

Imagem escaneada pelas autoras.

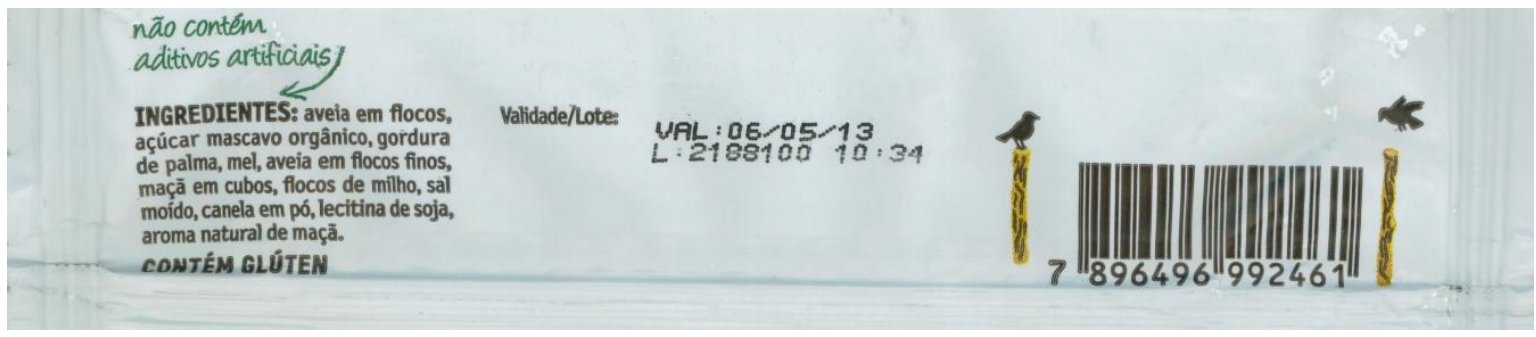

A tipografia usada é sem serifa (como em "Granola Caseira") e arredondada, o que dá um ar de simplicidade. Em algumas partes da embalagem, ela imita a escrita cursiva (como em "Tradicional" e em "sem adição de açúcar"), o que humaniza o produto. Essa mesma sensação é provocada, na embalagem da barra de cereais mostrada na Figura 2, por elementos como desenhos (os postes ao lado do código de barras) que parecem feitos por alguém sem intenção, apenas para "matar o tempo", e indicações soltas na embalagem (a seta que aponta para a lista de ingredientes e traz um comentário), que simula uma colocação de um outro consumidor sobre a informação habitual, exigida por lei, que é a lista de ingredientes.

Fig. 3 - Embalagens de produtos ultraprocessados Mãe Terra: sopa, salgadinhos e cookies. Fonte: http://www.maeterra.com.br/produtos
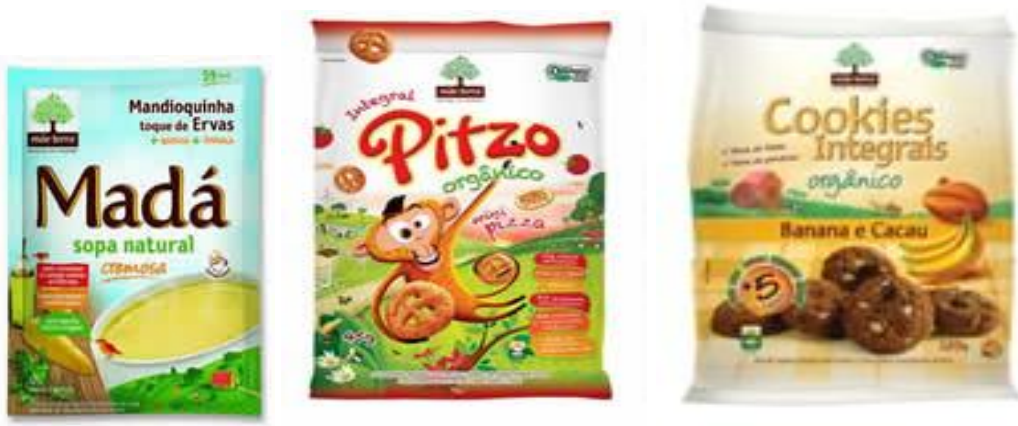

As embalagens dos alimentos ultraprocessados, reproduzidas na Figura 3, apresentam um padrão visual bastante diferente do dos alimentos minimamente processados. A ilustração da casa no campo, presente na largura inteira do rodapé de todas as embalagens dos grãos integrais, aparece em metade do rodapé da sopa; como pano de fundo e diluída pela presença de outros elementos chamativos (como o macaco) na embalagem de salgadinho; apenas evocada pelo desenho de algumas montanhas na parte 
Análise semiótica da marca mãe terra: o potencial comunicativo de suas embalagens

central da embalagem dos cookies, na linha do horizonte. Além disso, as embalagens dos grãos integrais e dos produtos prontos para o consumo diferem nas cores, mais variadas e quentes no segundo caso.

Os símbolos associados a informações nutricionais complementares ("fonte de fibras", por exemplo) são um padrão criado pela Mãe Terra para identificar características comuns entre diversos produtos da marca. Trata-se de uma forma voluntária, mais simpática e clara de destacar o que já está dito na tabela nutricional obrigatória, no verso da embalagem. Assim, esses símbolos funcionam também como índices, pois apontam para características numéricas reais do produto. As informações verbais acompanhadas desses símbolos-índices indicam que o produto é saudável por possuir tais características.

Além de ressaltar que seus produtos são naturais e saudáveis, a Mãe Terra também faz questão de dizer que seus processos produtivos respeitam sete princípios de minimização de impactos ambientais adotados pela empresa. Se o faz sutilmente por meio da cor verde, o faz explicitamente por meio de selos (IBD e Orgânico Brasil) e mais símbolos, apresentados em parte não frontal das embalagens e explicados no site da marca.

Fig. 4 - Os sete aspetos do impacto ambiental dos produtos Mãe Terra, declarados nas embalagens na forma de símbolos.

Fonte: http://www.maeterra.com.br/pensandobem/index1.asp

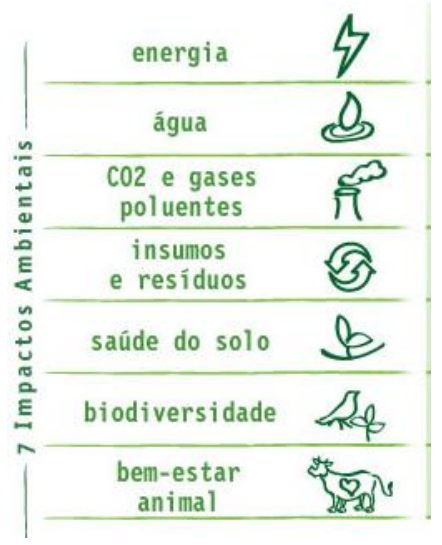

Assim, na linha de pensamento de Peirce, descrita por Santaella (2007), podemos apontar três significantes imediatos relevantes para esse padrão de rotulagem. No nível emocional, os signos da marca que "lembram" a natureza e o caseiro transmitem conforto e segurança (como o lar). No nível energético, comunicam a importância de fazer escolhas alimentares informadas e conscientes com critérios mais amplos. No nível lógico, têm a 
Análise semiótica da marca mãe terra: o potencial comunicativo de suas embalagens

potência de mobilizar o consumidor no sentido de um exame mais atento dos produtos disponíveis no mercado e o atrair para a fidelidade aos produtos Mãe Terra.

\subsection{Ponto de vista singular-indicativo}

A partir dos elementos apresentados na seção anterior, podemos concluir que os produtos Mãe Terra são destinados a consumidores que valorizam a alimentação saudável. Porém, seu preço, em pesquisa em lojas de varejo online e físicas realizada em novembro/dezembro de 2012 pelas autoras, é próximo ao das demais marcas que vendem a mesma categoria de produtos ou similares, ou seja, eles têm um posicionamento de preço intermediário, não buscando apenas um nicho de consumidores mais nutricionalmente conscientes. Essa indicação é reforçada pela distribuição relativamente intensiva, de acordo com pesquisa das autoras: os produtos de preço da marca estão disponíveis em lojas especializadas, como Mundo Verde, mas também em grandes redes varejistas, como CBD.

Como a maior parte dos produtos é considerada minimamente processada ou ingrediente, pois requerem preparação pelo consumidor, entende-se que as pessoas que o compram valorizam a alimentação no lar.

O "alargamento" do conceito de natural e caseiro para produtos ultraprocessados da marca, como salgadinhos e sopas prontas, nos permite deduzir que, assim como cresce a consciência da sociedade sobre a importância de uma alimentação mais saudável, proposta principal da marca Mãe Terra, cresce também o mercado de alimentos prontos, abrindo espaço para a marca expandir seus atributos característicos para novas categorias.

O tipo de embalagem dos lançamentos cookies e salgadinhos (Figura 3) permite concluir que eles são voltados ao público infantil (ainda que talvez não exclusivamente). Nos salgadinhos, o principal elemento da embalagem é o "mascote" e, nas cookies, o produto reproduzido em imagem (sem a janela que mostra o produto em si, característica das demais embalagens), envolto em cores mais fortes.

Há uma série de selos e elementos utilizados para destacar as características dos produtos, o que demonstra que a empresa procura ajudar o consumidor a entender sua oferta e se coloca como responsável por ajudá-lo a tomar consciência sobre fatores relacionados à alimentação saudável e sustentabilidade. Esse tipo de postura é condizente com uma marca que está associada ao arquétipo maternal. 
Análise semiótica da marca mãe terra: o potencial comunicativo de suas embalagens

A origem da empresa e dos produtos é evocada e se relaciona a um estilo de vida da fazenda, bucólico, de contemplação, além de saudável e sustentável.

O uso de símbolos "mimosos" e certificações para informar o consumidor tanto sobre características nutricionais dos produtos quanto sobre processos produtivos indica uma estratégia pensada para facilitar a associação entre uma alimentação saudável e a sustentabilidade, e ao mesmo tempo entre a marca e os cuidados simultâneos com a saúde pessoal e com o planeta.

Apesar de apelos para o "consumo verde" terem se tornado comuns no marketing de diversas categorias de produtos, a maioria dos rótulos de alimentos no Brasil ainda não associa diretamente as informações sobre nutrição com informações sobre os impactos socioambientais do produto e da marca. Nesse aspecto, a Mãe Terra apresenta uma comunicação mais integrada, diversa da encontrada nas embalagens das marcas concorrentes. Em comparação com outras marcas, os signos da Mãe Terra têm potencial para modificar a forma de o consumidor avaliar os produtos da concorrência e fazer suas escolhas alimentares.

\subsection{Ponto de vista convencional-simbólico}

Com esse conjunto de signos presentes nas embalagens a marca potencialmente comunica que (a) a empresa que a administra faz o bem para as pessoas e para o planeta; (b) consumir seus produtos é uma forma de ser saudável e representa um estilo de vida natural; (c) consumir seus produtos é uma forma de cuidar da natureza e do meio ambiente; (d) consumir seus produtos é uma forma de valorizar a produção nacional e favorecer fornecedores ligados a determinadas culturas; (e) ela não é uma grande empresa; (f) ela tem autoridade e pode ensinar o consumidor a comer melhor, evocando uma relação "de mãe para filho".

\section{RITUAIS DE CONSUMO DE ALIMENTOS}

$\mathrm{Na}$ sociedade de consumo, os produtos e as marcas são consumidos de forma identitária, ou seja, com a finalidade de transferir para os consumidores valores desejáveis que esses produtos e marcas supostamente possuem. Segundo McCracken (2003) essa 
Análise semiótica da marca mãe terra: o potencial comunicativo de suas embalagens

transferência se dá na forma de rituais e por meio de instrumentos como a publicidade e a moda.

Primeiramente, diz McCracken (2003), a sociedade constitui seus princípios e categorias culturais, dos quais derivarão valores transferíveis ao processo de consumo. No caso da alimentação, podemos identificar no caldeirão de princípios culturais da sociedade ocidental: uma valorização da natureza (ainda que como abstração), o desejo de maior conexão com a natureza, a epidemia de obesidade e doenças crônicas associadas, a valorização do corpo magro e sarado e uma maior valorização da alimentação natural e saudável e da prática regular de atividade física. Observa-se ainda uma valorização da postura ética perante a preservação da natureza, o bem-estar animal e os problemas sociais no mundo inteiro, o que cada vez mais resulta numa maior culpabilização das pessoas e das empresas capitalistas pelos problemas ambientais e sociais.

Nesse contexto, emerge o mercado de "consumo verde", em que as empresas se apresentam à sociedade como benfeitoras e os consumidores, como autores de escolhas conscientes em nome do bem. Marcas e produtos associados à solução dos problemas nutricionais, ambientais e sociais são assim elevados a uma categoria especial e tornam-se desejados por consumidores que querem se sentir autores de escolhas benéficas - para si e para o resto do mundo. É o que permite à Mãe Terra apresentar-se como se apresenta: amiga da natureza e da boa nutrição, para o bem do planeta e da silhueta das pessoas.

Por meio dos signos da marca apresentados anteriormente - e com a ajuda de inúmeros produtos culturais produzidos por terceiros, como filmes, reportagens e livros sobre a alimentação natural e sustentável -, a Mãe Terra transfere para si os valores culturalmente constituídos na sociedade ocidental e torna-se carregada de significado.

Ao identificar nos produtos da marca os quesitos valorizados na sociedade, o consumidor deseja adquiri-los para si e tornar-se ele também um possuidor da conexão com a natureza, da capacidade de se alimentar bem e da disposição para cuidar da natureza. Em mais uma etapa de transferência, conforme descrito por McCracken (2003), o consumidor se vale de rituais de posse e troca para apropriar-se das características dos produtos de apelo saudável que consome. Sendo ele um consumidor de produtos com fibras produzidos sem abuso de energia ou sem afetar a biodiversidade, ele crê tornar-se um cidadão consciente, que além de manter seu corpo são ainda contribui para minimizar a degradação da natureza e da sociedade. 
Análise semiótica da marca mãe terra: o potencial comunicativo de suas embalagens

Ainda segundo McCracken (2003), essa transferência de valor se dá também entre produtos. Uma vez atribuídos e consolidados aos produtos de uma marca determinados valores, estes podem ser transferidos por meio dos rituais de consumo a novas linhas de produto da mesma marca. Nas palavras de McCracken (2003: 153)

\begin{abstract}
A consistência cultural dos bens de consumo reflete (1) a natureza do significado contido nas coisas, (2) o modo pelo qual este significado adentra nas coisas, (3) a maneira através da qual o significado das coisas é comunicado pelo 'código objeto'. (...) O significado dos bens de consumo deriva da posição que ocupam em um sistema de bens e da relação deste sistema com um sistema de categorias culturais. (...) É esta correspondência entre as categorias culturais e os bens de consumo que ajuda a determinar quais serão os bens que irão andar juntos. Todas as categorias de produtos são organizadas a fim de corresponder ao mesmo conjunto de categorias culturais. Isto significa, forçosamente, que todas as categorias de produtos devem também corresponder umas às outras. É possível, portanto, tomar cada uma das categorias culturais e alinhá-las com cada uma das categorias de produtos, e assim suas distinções internas figurarão em paralelo. Quando isto é feito, o equivalente estrutural de uma marca em uma categoria se torna evidente em todas as outras.
\end{abstract}

Quando a Mãe Terra, ao final da década passada, alargou seu mix de produtos, acrescentando a ele produtos semiprontos e prontos para o consumo, alguns deles direcionados às crianças, os atributos até então assegurados para seus alimentos minimamente processados ("naturais de verdade") puderam ser transferidos a esses novos itens, por mais diferentes que estes possam ser em seus aspectos nutricionais e produtivos. Ao usar nos produtos prontos para o consumo os mesmos signos da marca usados nos produtos tradicionais, a Mãe Terra antecipa para o consumidor a percepção de que todos os produtos da marca são feitos com as mesmas preocupações nutricionais e ambientais e assim facilita a associação da marca, e não apenas de cada produto isoladamente, com uma alimentação saudável e ambientalmente responsável.

As embalagens dos itens ultraprocessados da Mãe Terra mantêm os signos da marca, mas com algumas diferenças. A informação nutricional complementar continua lá, assim como a cor verde, a ilustração bucólica (com menos destaque) e a tipologia "meiga". Mas cores mais quentes dividem o espaço com o branco e o verde, tornando as embalagens mais chamativas para um público que possivelmente ainda está menos interessado em alimentação saudável e ecológica do que os consumidores que conheceram a Mãe Terra de 1979 e mais interessado em praticidade. É uma maneira de formar uma nova geração de consumidores.

\title{
6. DISCUSSÃO
}


Do ponto de vista do marketing, a estratégia de comunicação usada nas embalagens da Mãe Terra tem potencial para atrair, conscientizar e modificar hábitos do consumidor. Do ponto de vista da informação para escolhas mais saudáveis, no entanto, a análise deve levar considerar outros fatores.

Para o consumidor comum, não é fácil identificar quais são os produtos processados mais saudáveis. Compará-los adequadamente é tarefa para especialistas. Para uma escolha verdadeiramente informada, o consumidor deveria: comparar todos os aspectos nutricionais dos produtos, checando se as vitaminas e minerais são sintéticos ou naturalmente presentes no alimento; saber o teor de açúcar nos alimentos, o que nem sempre é informado; verificar o percentual de ingredientes integrais na composição dos produtos, identificando em que medida eles foram processados; observar se o produto contém substâncias indesejáveis, como aditivos cosméticos ou resíduos de agrotóxicos; pensar se o produto será consumido em grupo ou individualmente; lembrar se o produto tem alguma conexão com a cultura local; saber se o produto contém algum organismo geneticamente modificado; associar a marca com bons índices de responsabilidade social, e por aí vai. Nenhuma embalagem de alimento vendido no Brasil hoje informa tudo isso.

As embalagens Mãe Terra têm selos de produção orgânica, mas não informam em que medida a qualidade de orgânico torna um alimento mais ou menos saudável, nem permitem pôr numa mesma balança os cuidados nutricionais e ambientais. Os salgadinhos orgânicos podem conter mais gordura saturada (2,2 g a cada 25 gramas de produto) que não orgânicos similares (um concorrente sabor queijo, não orgânico, tem $0,8 \mathrm{~g}$ de gordura saturada na mesma porção), devido ao uso de gordura de palma orgânico (rica em gordura saturada). Mas possivelmente terão menos resíduos de agrotóxicos do que os não orgânicos. Possível mas não certamente, uma vez que a quantidade de resíduos de agrotóxicos presente nos não orgânicos não é informada. Afinal, será que sem essas informações detalhadas é possível saber qual opção é mais saudável?

Se tiver tudo isso em mente, o consumidor saberá que precisa de mais informação para fazer escolhas verdadeiramente informadas. Se não tiver em mente nada disso experiência colateral insuficiente, conforme a teoria de Peirce na obra de Santaella (2007) -, o consumidor poderá ser facilmente convencido pelos signos das marcas e basear sua dieta em produtos pouco nutritivos, acreditando estar se alimentando de forma saudável. 
Análise semiótica da marca mãe terra: o potencial comunicativo de suas embalagens

A Mãe Terra é, sem dúvida, uma marca que se posiciona como uma escolha saudável e sustentável e os seus signos têm o potencial de gerar esses sentidos. Esses dois atributos principais por ela trabalhados são valorizados socialmente e explorados por diversas empresas. Porém, há uma questão ética com que a legislação deve se preocupar, considerando ao mesmo tempo a experiência colateral dos consumidores e a parcialidade da informação contida nesses signos. A potência de significado está presente, mas será que ela ajuda de fato o consumidor a fazer melhores escolhas? Conclui-se, assim, que há espaço para pesquisas sobre dois aspectos fundamentais da comunicação sobre alimentação saudável e sustentável com o consumidor: a operacionalização dos conceitos a serem comunicados (o que é de fato saudável e sustentável?) e as linguagens mais adequadas para representar esses conceitos.

\section{REFERÊNCIAS BIBLIOGRÁFICAS}

AGÊNCIA NACIONAL DE VIGILÂNCIA SANITÁRIA (Anvisa). "Resolução RDC n 259, de 20 de setembro de 2002" in Diário Oficial da União; Poder Executivo, Brasília, DF, 23 set 2002. Disponível em: <http://portal.anvisa.gov.br/wps/wcm/connect/36bf398047457db389d8dd3fbc4c67 35/RDC_259.pdf?MOD=AJPERES>

"Resolução RDC n n $^{360, \text { de }} 23$ de dezembro de 2003" in Diário Oficial da União; Poder Executivo, Brasília, DF, 26 dez 2003. Disponível em: <http://portal.anvisa.gov.br/wps/wcm/connect/1c2998004bc50d62a671ffbc0f9d5b2 9/RDC_N_360_DE_23_DE_DEZEMBRO_DE_2003.pdf?MOD=AJPERES> “Resolução da Diretoria Colegiada RDC no 54, de 12 de novembro de 2012". Disponível em: <http://portal.anvisa.gov.br/wps/wcm/connect/630a98804d7065b981f1e1c116238c 3b/Resolucao+RDC+n.+54_2012.pdf?MOD=AJPERES>

BARBOSA, V. "Mãe Terra mede impacto ambiental de seus produtos", in Revista Exame, Editora Abril, São Paulo, 1/11/2011. Disponível em: <http://exame.abril.com.br/meio-ambiente-e-energia/noticias/mae-terra-medeimpacto-ambiental-de-seus-produtos $>$. Acesso em: 4/12/2012.

BATEY, M. O significado da marca: como as marcas ganham vida na mente dos consumidores. Rio de Janeiro: Best Business, 2010. 
LOBSTEIN, T. \& DAVIES, S. "Defining and labelling 'healthy' and 'unhealthy' food", in Public Health Nutrition, 12, 2009, p. 331-340.

MÃE TERRA - site da empresa <http://www.maeterra.com.br/site/>. Acesso em: Nov/Dez 2012.

MCCRACKEN, G. Cultura \& Consumo. Rio de Janeiro: MAUAD, 2003.

MCCRACKEN, G. "Cultura \& Consumo: uma Explicação Teórica da Estrutura e do Movimento do Significado Cultural dos Bens de Consumo", in RAE, $\mathrm{n}^{\circ} 1$, vol.47, São Paulo, jan-mar 2007, p. 99-115.

MONTEIRO, CA; LEVY, RB; CLARO, RM; CASTRO, IRR \& CANNON, G. "A new classification of foods based on the extent and purpose of their processing", in Cad. Saúde Pública, ${ }^{\circ} 26$, vol 11, Rio de Janeiro, nov 2010, p. 2039-2049.

PEREZ, C. Signos da marca: expressividade e sensorialidade. São Paulo: Thomson Pioneira Learning, 2004.

SANTAELLA, L. Semiótica Aplicada. São Paulo: Thomson Learning, 2007.

WORLD HEALTH ORGANIZATION (WHO). "Global strategy on diet, physical activity and health" (2004).

Artigo submetido: novembro de 2012

Artigo aprovado: dezembro de 2012 